\title{
Internet Gaming Disorder: a review on etiological factors, psychiatric comorbidity and clinical approach
}

\section{Introduction}

Internet Gaming Disorder (IGD) and Gaming Disorder are included in section III of the $5^{\text {th }}$ edition of the Diagnostic and Statistical Manual of Mental Disorders (DSM-5), as well as in the $11^{\text {th }}$ edition of the International Classification of Diseases (CID-11), thus reflecting their increasing importance as a significant mental health concern $(1,2)$. This should be accompanied by the raising of awareness on behalf of health community services regarding this condition, including etiology, psychiatric comorbidities and clinical management.

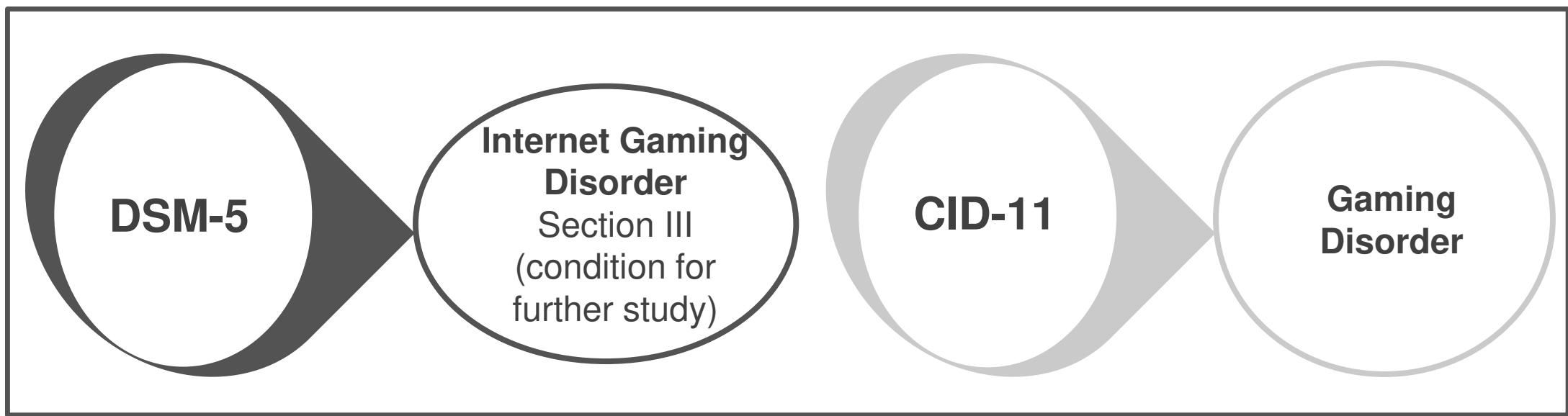

\section{Etiology $\mathbf{y}_{(3,4,5)}$}

\section{Treatment $t_{6,7}$}

\begin{tabular}{|c|c|c|}
\hline $\begin{array}{l}\text { Videogame } \\
\text { structural } \\
\text { characteristics }\end{array}$ & \multicolumn{2}{|c|}{$\begin{array}{l}\rightarrow \text { Massively Multiplayer Online games > Shooters > Multiplayer } \\
\text { Online Battle Arena games > Real-Time strategy games } \\
\rightarrow \text { Online Videogames that don't allow the user to pause the game: more } \\
\text { addictive than offline single player games }\end{array}$} \\
\hline $\begin{array}{c}\text { Individual } \\
\text { characteristics }\end{array}$ & $\begin{array}{l}\rightarrow \text { Novelty seeking } \\
\rightarrow \text { Avoidant personality } \\
\rightarrow \text { Cluster B personality } \\
\rightarrow \text { Lower self-esteem }\end{array}$ & $\begin{array}{l}\rightarrow \text { Higher rates of impulsivity } \\
\rightarrow \text { Difficulties in emotional regulation } \\
\quad \text { (> emotion suppression and } \\
\quad<\text { cognitive reevaluation) }\end{array}$ \\
\hline Motivation & \multicolumn{2}{|c|}{$\begin{array}{l}\rightarrow \text { The need to belong to a group (even if it is a "virtual" one) } \\
\rightarrow \text { Using videogames as a way to run from problems } \\
\rightarrow \text { FOMO (Fear of Missing Out): desire to stay continually connected with } \\
\text { what others are doing }\end{array}$} \\
\hline $\begin{array}{l}\text { Sociocultural } \\
\text { context }\end{array}$ & $\begin{array}{l}\rightarrow \text { Family conflicts } \\
\rightarrow \text { Parents with psychiatric } \\
\text { disorder } \\
\rightarrow \text { History of physical abuse }\end{array}$ & $\begin{array}{l}\rightarrow \text { Insecure attachment patterns } \\
\rightarrow \text { Low school performance } \\
\rightarrow \text { Uninvolved parenting }\end{array}$ \\
\hline
\end{tabular}

There are no randomized trials showing effectiveness of pharmacological and nonpharamacological approaches

Cognitive-Based Treatment (CBT): $\rightarrow$ CBT for 6 months in patients with IGD: reduction of cognitive distortions and symptoms $\rightarrow$ Self Discovery Camp Treatment $(9$ days without eletronic devices $+\mathrm{CBT}$ ): short and long term improvement

Emotional Regulation Techniques $\rightarrow$ Reduction of anxiety and depressive symptoms

$\rightarrow$ Reduction of IGD symptoms

Bupropion

$\rightarrow$ Positive effects on nicotine and cocain addiction and gambling disorder

$\rightarrow$ Patients with IGD: reduction of craving and time spent playing videogames after 6 month treatment with Bupropion

\section{Psychiatric comorbidity ${ }_{(3,4)}$}

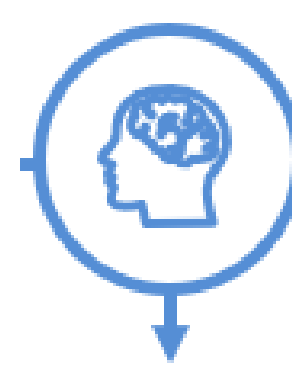

Depressive Disorders

$\rightarrow$ The most frequent comorbidity

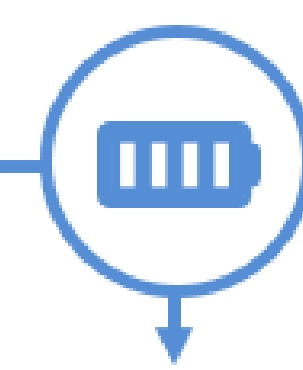

ADHD

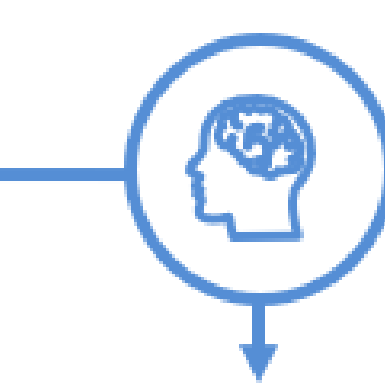

Autism

Spectrum Disorder

$\rightarrow$ Patients with ADHD: $13 \%$ have IGD

\section{Conclusion}

Although universal recognition of IGD as a mental health disease isn't still widely accepted, efforts have been made to identify etiological factors, possible psychiatric comorbidities and potential beneficial treatments. Research regarding this thematic should continue to be performed in order to allow clinicians to better manage patients with IGD. 